\title{
Thrombophilia and multiple thrombosis post pancreatectomy due to insulinoma: Case report
}

\author{
Pablo Weber-Alvarez ${ }^{1 *}$, Luis Alejandro Weber-Sánchez ${ }^{2}$ and Luis Gerardo Sánchez-Brito ${ }^{3}$ \\ ${ }^{1}$ General Physician, Hospital Angeles Lomas Huixquilucan, Mexico \\ ${ }^{2}$ Department of General Surgery, Angeles Lomas Hospital, Mexico \\ ${ }^{3}$ Department of General Surgery, Beneficencia Española Hospital, Puebla, Mexico
}

\begin{abstract}
The relationship between thromboembolic disease and benign and malignant tumors has been extensively described. Diagnosis and treatment of these thrombotic events such as deep venous thrombosis (DVT) and pulmonary thromboembolism (PTE) occurs late because this association continues to be unnoticed increasing morbidity and mortality.
\end{abstract}

We present the case of a patient who underwent pancreatectomy due to insulinoma and presented recurrent thrombosis.

\section{Introduction}

Thromboembolic disease in patients with benign or malignant tumors is a complication difficult to treat that constitutes the second cause of death in cancer patients. The risk of recurrence after a first episode is greater in patients with malignant neoplasm with poor prognosis [1]; because of this, their life expectancy decreases dramatically. Therefore, it is important to be aware of this association and implement early preventive measures, especially in those patients with other risk factors such as surgery.

\section{Case report}

This is the case of a 49-year-old man who started his condition four days before his admission to the hospital, presenting abdominal pain in mesogastrium radiated to the left flank, asthenia, adynamia, nausea and vomit in multiple occasions. He referred also $10 \mathrm{~kg}$ of weight loss in the last 2 months. On physical examination he had icteric skin and sclera and abdominal pain in superficial and deep palpation in mesogastrium and left flank. As relevant factors he referred a previous history of many months of unexplained weakness, palpitations and tremor.

Abdominal CT scan showed a $3 \mathrm{~cm}$ solid mass in the head of the pancreas without involvement of the choledocus. Total pancreatectomy was performed with duodenum preservation and choledoco-duodenal anastomosis, extracting a well-defined tumor in the head of the pancreas of approximately $3.5 \mathrm{~cm}$ (Figure 1). Pathology reported a tumor of low malignant potential and little mitotic activity diagnosed as insulinoma.

On the first day after surgery he presented fever, tachycardia, asthenia, adynamia and poor general condition. An abdominal and chest CT scan was performed which suggested a pneumonia, so he was started on antibiotics, however, he continued with poor general condition and the fever persisted so a new CT was carried out, showing partial thrombosis of the left iliac vein (Figure 2) and also thrombosis of the left jugular vein was found on ultrasound (Figure 3). Because of the impairment of his clinical condition and image findings, the patient was taken to the intensive care unit for close monitoring

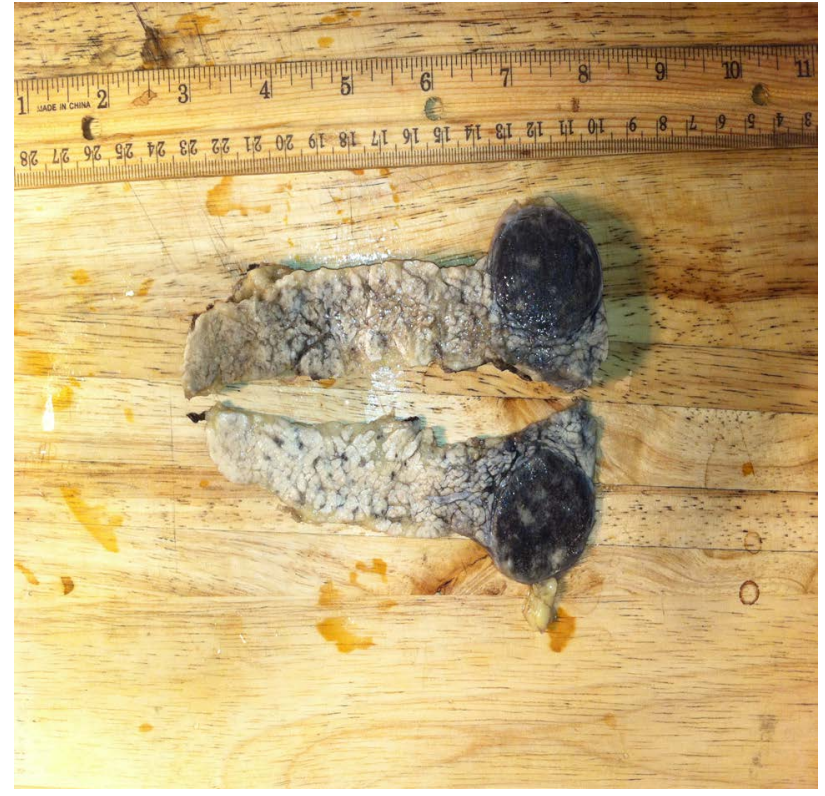

Figure 1. Pancreatic head tumor mass

and antithrombotic prophylaxis. After five days there, he presented again hyperthermia, dyspnoea and hypoxemia. Another CT showed pulmonary embolism (Figure 4), so it was decided to place a vena cava

*Correspondence to: Pablo Weber-Alvarez, MD, Vialidad de la Barranca s/n C410, Valle de las Palmas, Huixquilucan, 52763, Estado de México, México, Tel: 52469527; E-mail: pbl.weber@hotmail.com

Key words: thrombosis, thrombophilia, pancreatic tumors, thromboembolic disease, neoplasm, surgery

Received: October 04, 2018; Accepted: October 12, 2018; Published: October 19,2018 


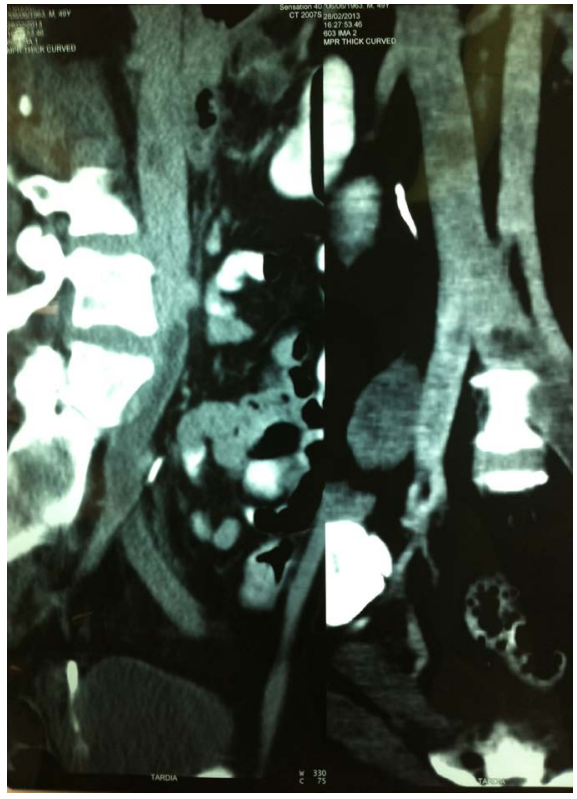

Figure 2. Thrombosis of the left iliac vein
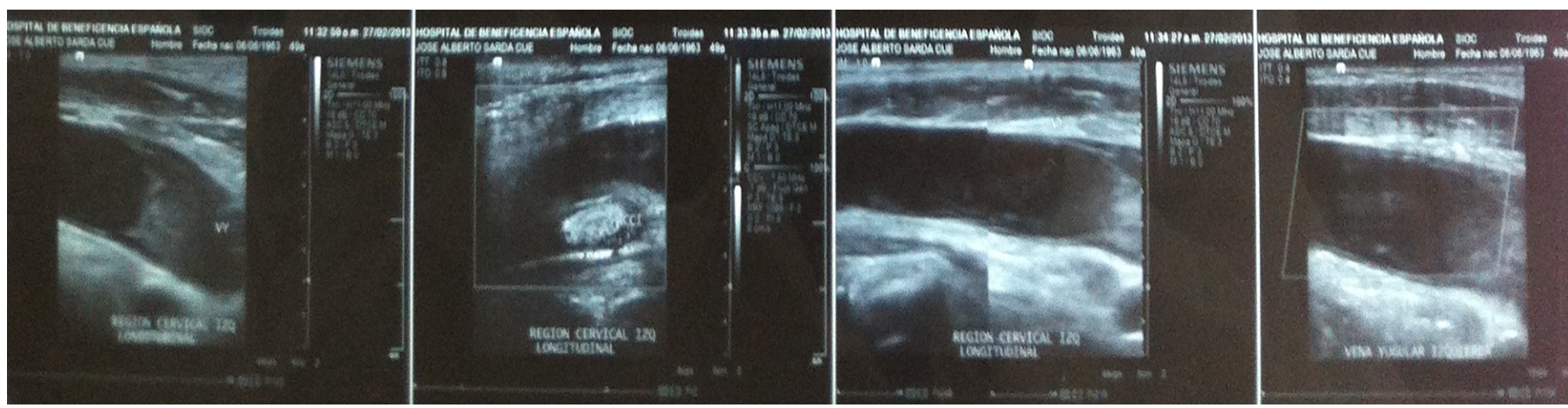

Figure 3. Thrombosis of the left jugular vein

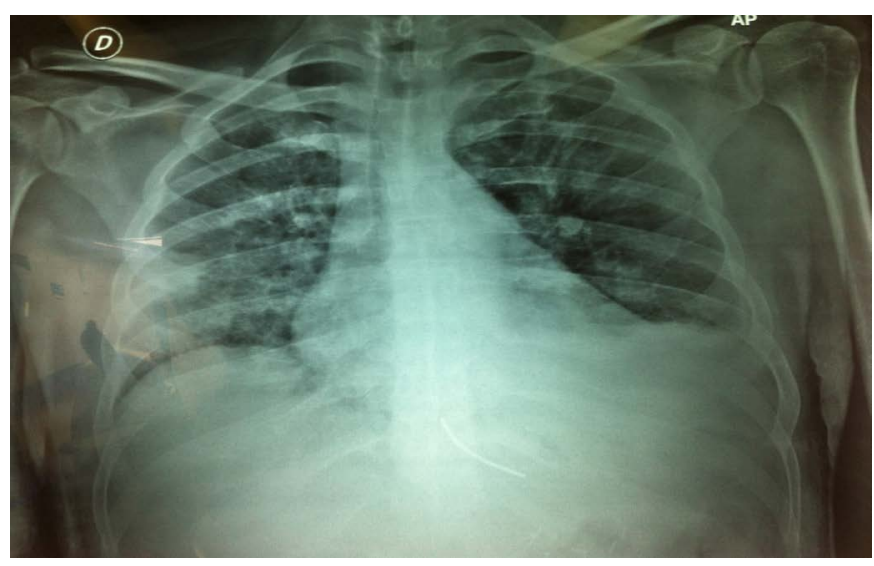

Figure 4. Plate corresponding to pulmonary thromboembolism (PTE)

filter. Ten days later, due to improvement of his condition he was taken out of the intensive care area to continue his treatment. Three days later a parasplenic abscess was detected on a new CT scan that was drained by puncture uneventfully. At the time of discharge he was stable with treatment based on anticoagulants and pancreatic replacement therapy, and he remained without any further thrombotic episodes recovering of the surgical procedure.

\section{Discussion}

Thromboembolic disease is one of the most well-known complications in patients with benign or malignant tumors [2,3], however this association is often forgotten. It manifests mainly as deep venous thrombosis (DVT) and pulmonary thromboembolism (PTE) and constitutes an emergency itself since it is the second cause of 
death in these patients, both hospitalized and outpatients [4]. Salama reported that during hospital admission, neoplastic patients had a higher incidence of venous thromboembolic disease, and necropsies of patients in his institution showed that $14 \%$ of patients with neoplasms of any kind have died due to PE during their admission, versus $8 \%$ of those who do not had tumors [5]. The incidence of thrombembolic disease associated with tumors, is not certainly known. Some studies estimate that it varies from 1 to $8 \%$ reaching up to $20 \%$ [5] in high-risk patients. Multiple factors that can contribute to the presentation of this condition such as cancer type, advanced stages and the clinical patient's condition.

One of the most frequent neoplasms associated with this phenomenon is pancreatic cancer, especially the mucin-producing tumors, ovarian, brain and colorectal cancer. Levitan et al. [6] reported the incidence of thrombosis according to the type of cancer and its presentation, in a meta-analysis in which 7,238 patients diagnosed with DVT or PE and cancer were included. The incidence of venous thromboembolic disease in ovarian cancer was $120 / 10,000$, in central nervous system cancer $117 / 10,000$ and in pancreatic cancer 110/10,000. Waild et al. [7] performed a retrospective study with 201 patients with pancreatic cancer, of these $58(28.9 \%)$ presented thromboembolic disease, 37 (63.7\%) DVT, 11 (18.9\%) PTE and 10 (17.2\%) both.

Cancer and thromboembolic disease are closely related, some of the known causes are the production of procoagulant substances and the inflammatory response, the suppression of natural anticoagulants, fibrinolysis and endothelial damage produced by the tumor. These factors are frequent in patients with high grade malignant lesions or with metastasis. On the other hand, the activation of coagulation processes because of any etiology can influence the tumor growth and metastatic spread [8-10]. Because of this, in patients' recurrent thrombotic episodes without known cause, an exhaustive search for an occult tumor should be carried out since it can be found in up to $10 \%$ of the cases [11]. So, in some patients with cancer or known hypercoagulability states, it is important to establish early prophylaxis therapy to prevent recurrent thrombotic events and death.

In surgical patients in general, thromboembolic disease can occur in 1 out of 4 patients being fatal in many cases. In surgical oncologic patients, the risk of presenting this entity is double; therefore, thromboprophylaxis before and after the surgical procedures is highly recommended. Some of the most recognized causes that can increase this risk are: prolonged surgical time, the extension of the tumor resection and involvement of adjacent vessels. Other contributing factors are placement of venous central catheters, although they are essential tools for management of oncological patients for the administration of chemotherapy, transfusions or parenteral nutrition when necessary, the associated endothelial damage can induce thrombosis, with varying frequency from 4 to $80 \%$, so special care should be taken [12].

The patient we reported here, had thromboembolic disease manifested as thrombosis of the left jugular vein, left iliac vein and later PTE after surgery for a pancreatic cancer. The use of low molecular weight heparin adjusting the dose according to the risk in each patient in addition to the use of measures to avoid venous stasis are the prophylactic methods of choice, however these may not be sufficient so the implementation of other therapies such as the placement of vena cava filter as in the case presented here are advisable $[12,13]$.

\section{Conclusion}

Thrombotic complications that may arise associated with tumors are well known, frequent and must be prevented. Thorough search for occult cancer in patients with idiopathic recurrent thrombotic disease should be done and antithrombotic prophylaxis should be implemented early to prevent such complications and decrease morbidity and mortality.

\section{Financing}

No sponsorship of any kind was received to carry out this study.

\section{Conflict of interests}

The author (or authors if they are more than one) declare (or declares) any conflict of interests.

\section{References}

1. Prandoni P, Lensing AW, Piccioli A, Bernardi E, Simioni P, et al. (2002) Recurrent venous thromboembolism and bleeding complications during anticoagulant treatment in patients with cancer and venous thrombosis. Blood 100: 3484-3488. [Crossref]

2. Sorensen HT, Mellemkjaer L, Steffensen FH (1998) The risk of a diagnosis of cancer after primary deep venous thrombosis or pulmonary embolism. N Engl J Med 338:1169.

3. Monreal M, Fernandez LJ, Perandreu J (1997) Occult cancer in patients with venous thromboembolism: Which patients, which cancers. Thromb Haemost 78:1316.

4. Pineo GF, Brain MC, Gallus AS, Hirsh J, Hatton MW, et al. (1974) Tumors, mucus production, and hypercoagulability. Ann N Y Acad Sci 230: 262-270. [Crossref]

5. Salama P1 (2004) [Thrombosis and cancer]. An Sist Sanit Navar 27 Suppl 3: 45-51. [Crossref]

6. Levitan N, Dowlati A, Remick SC, Tahsildar Hi, Sivinski LD, et al. (1999) Rates of initial and recurrent thromboembolic disease among patients with malignancy versus those without malignancy: risk analysis using Medicare claims data. Medicine (Baltimore) 78:285-291. [Crossref]

7. Walid S, Yanhong D, Zilterman D, Lundberg B, Wasif MS (2010) Assessing Risk and Mortality of Venous Thromboembolism in Pancreatic Cancer Patients. Anticancer Res 30: 4261-4264. [Crossref]

8. Rickles FR (2001) Relationship of blood clotting and tumor angiogenesis. Haemostasis 31 Suppl 1: 16-20. [Crossref]

9. Falanga A, Barbui T, Rickles FR, Levine MN (1993) Guidelines for clotting studies in cancer patients. For the Scientific and Standardization Committee of the Subcommittee on Haemostasis and Malignancy International Society of Thrombosis and Haemostasis. Thromb Haemost 70: 540-542. [Crossref]

10. Santandreu BM, González LD, Castex FT, Seco GF, López AY (2015) Trombosis venosa profunda en adultos mayores con cáncer. Revista Cubana de Angiología Cirugía Vascular. 16:9-20.

11. Falanga A (2005) Thrombophilia in cancer. Semin Thromb Hemost 31: 104-110. [Crossref]

12. Olmosa PV, Gallob RM, Rebolloc AM, Ortegad BD, Docampoe IL, et al. (2015) Manejo de la enfermedad tromboembólica venosa en pacientes oncológicos: guíasde práctica clínica española. Consenso SEACV-SEOM. Med Clin 144:3-15.

13. Maus CG, Meillón L, Volkow P, Ruiz VA, Cornejo P, et al. (2013) Tratamiento de cáncer y trombosis: enfoque práctico. Revista de Investigación Clínica 65:174182

Copyright: (C2018 Alvarez PW. This is an open-access article distributed under the terms of the Creative Commons Attribution License, which permits unrestricted use, distribution, and reproduction in any medium, provided the original author and source are credited. 